\title{
Analysis and Design of S-shaped Microstrip Patch Antenna
}

\author{
Diwakar Singh ${ }^{1}$, Amit Kumar Gupta ${ }^{2}$, R.K.Prasad ${ }^{3}$, \\ ${ }^{1}$ M.tech Student, ${ }^{2}$ Lecturer, ${ }^{3}$ Associate Professor \\ ${ }^{1,2,3}$ Department of Electronics and Communication Engineering,Madan Mohan Malaviya Engineering College, \\ Gorakhpur, India
}

\begin{abstract}
This paper gives a compact analysis and design of S-shaped Microstrip patch antenna which is best suited for Wi-max application. The analysis and design is simulated over IE3D software Ver. 15.2. We have taken a definite ground plane of $50 \times 70 \mathrm{~mm}$ and patch size of $30 \times 50 \mathrm{~mm}$. The substrate thickness is taken as 1.6 $\mathrm{mm}$ and dielectric constant of 4.2 and loss tangent of 0.0013 .

The simulated result shows that the bandwidth is obtained in triple band- $7.79 \%$ at $0.262921 \mathrm{GHz}$ band, $13.45 \%$ at $1.53034 \mathrm{GHz}$ band and $28.0056 \%$ at $2.2382 \mathrm{GHz}$ band. The obtained gain is $3.96 \mathrm{dBi}$ at $2.33945 \mathrm{GHz}$. The obtained gain and bandwidth is best suited for Wi-max application.
\end{abstract}

Keywords: S shape, Ground plane, Patch Antenna, Triple Band.

\section{Introduction}

In communication systems antenna plays a vital role. Today is the era of microwave engineering where device size is very small. As we know that there are many conventional antennas which have high gain and bandwidth but they have big size and complex 3D geometry. So they are less efficient for microwave applications. To overcome this problem concept of Microstrip antenna is included. This antenna is small in size, cost effective and having 2D geometry. In spite of all these advantages this antenna has some disadvantages also like narrow bandwidth and gain, poor polarization etc. For enhancing the bandwidth and gain many methods are used like using different patch shape[1],[2],[7],[8], varying patch size, changing substrate thickness, using different dielectric substrate[4], using array configuration and stack configuration[3],[5] etc.

This paper gives analysis of S-shaped Microstrip antenna over IE3D software. The simulated result shows various curves from which we can calculate bandwidth, gain, directivity, antenna efficiency and radiation efficiency.

\section{Research Methodology}

The S-shaped Microstrip patch antenna is designed by cutting two slots in opposite direction and then this designed is simulated over IE3D software to obtain respective parameters. We have taken co-axial probe feed to fed this antenna because this feeding technique is much simple and have least radiation losses in comparison to other feeding technique like Microstrip line feed, Aperture coupled feed and Proximity coupled feed. In probe feeding we have chosen hit and trial method to calculate various parameters and the point where desirable result is obtained is taken as final point.

\section{Antenna Design}

The design of S-shaped patch antenna including dimensions is given below -

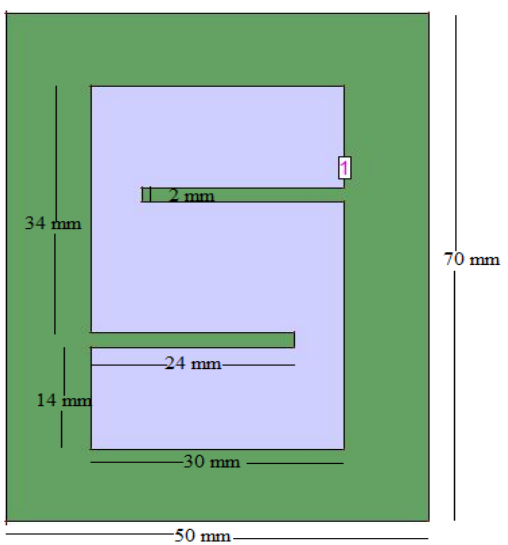

Fig.1: S-shaped Microstrip patch antenna 
The dimensions of antenna are indicated in figure and in the table also.

\begin{tabular}{|c|c|}
\hline Parameters & Size in $\mathbf{m m}$ \\
\hline Ground plane & $50 \times 70$ \\
\hline Patch size & $30 \times 50$ \\
\hline
\end{tabular}

Table. 1: Dimensions of antenna structure

\section{Results and discussion}

The simulated results shows various parameters. First of all return loss curve is considered to obtain the bandwidth, then we considered the VSWR curve to determine whether the obtained bandwidth is useful or not. VSWR should below 2 in desired frequency range. Then gain, directivity and efficiency curve is considered. Bandwidth and gain are the most desirable parameter in Microstrip patch antenna. Enhancing both bandwidth and gain is a challenging task. First curve that we consider is the Return loss curve to determine the bandwidth.

Return loss curve is given below -

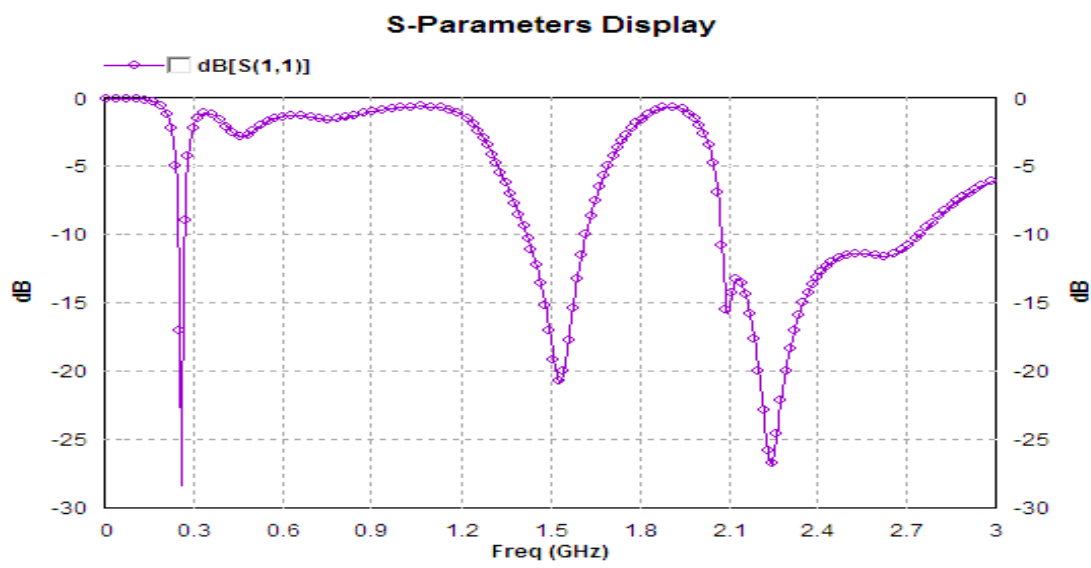

Fig. 2: Return loss Vs frequency curve

\section{Calculation of bandwidth}

From the figure it is the clear that curve crosses the $-10 \mathrm{~dB}$ line three times.

$f_{l 1}=0.252273 \quad f_{h 1}=0.272727 \quad f_{c 1}=0.2625$

$\%$ fractional Bandwidth ${ }_{1}=\frac{0.272727-0.252273}{0.2625} \times 100=\mathbf{7 . 7 9 \%}$

$f_{l 2}=1.41818 \quad f_{h 2}=1.62273 \quad f_{c 2}=1.520455$

$\%$ fractional Bandwidth ${ }_{2}=\frac{1.62273-1.41818}{1.520455} \times 100=\mathbf{1 3 . 4 5 \%}$

$f_{l 3}=2.07273 \quad f_{h 3}=2.74773 \quad f_{c 3}=2.41023$

$\%$ fractional Bandwidth ${ }_{3}=\frac{2.74773-2.07273}{2.41023} \times 100=\mathbf{2 8 . 0 0 5 6} \%$

Next important curve is VSWR. This curve should below 2 in desired frequency range for optimum result.

The VSWR curve is given as - 


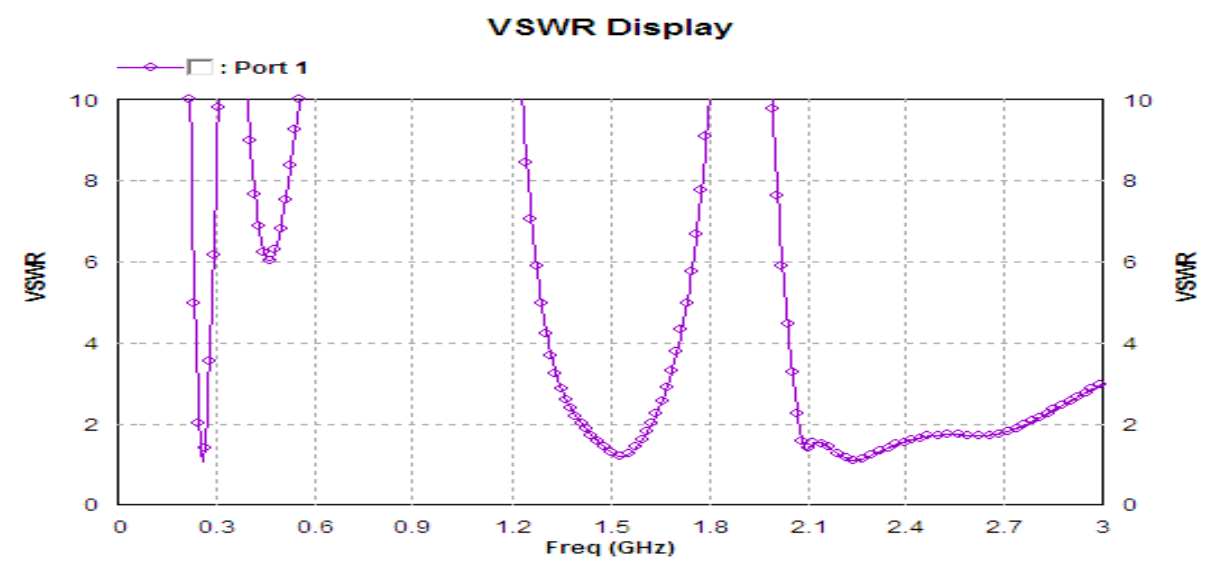

Fig.3: VSWR Vs Frequency curve

The VSWR is below 2 in desired range so obtained bandwidth is useful.

Next important parameter is gain which is given as -

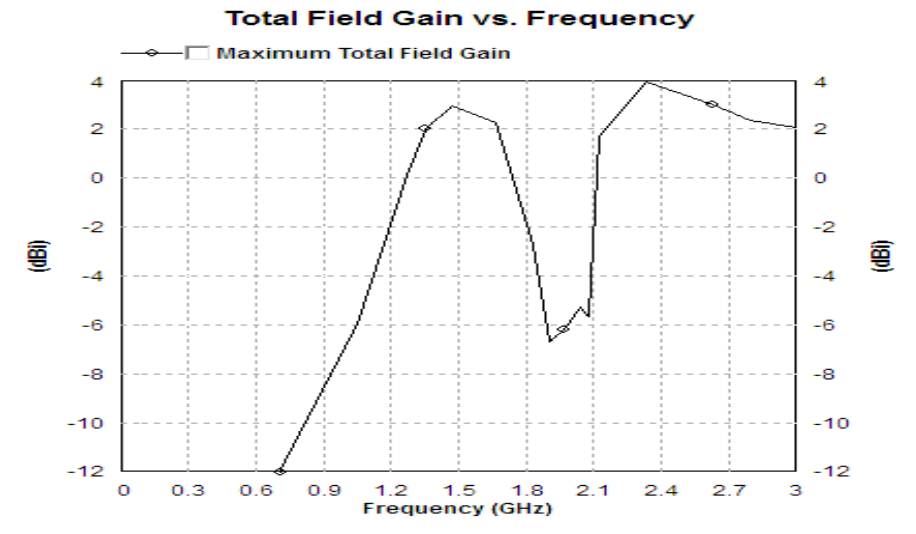

Fig.4: Gain Vs Frequency curve

The obtained gain is $3.96 \mathrm{dBi}$ at $2.33945 \mathrm{GHz}$ which is quite good.

Following figure gives information about directivity of this configuration -

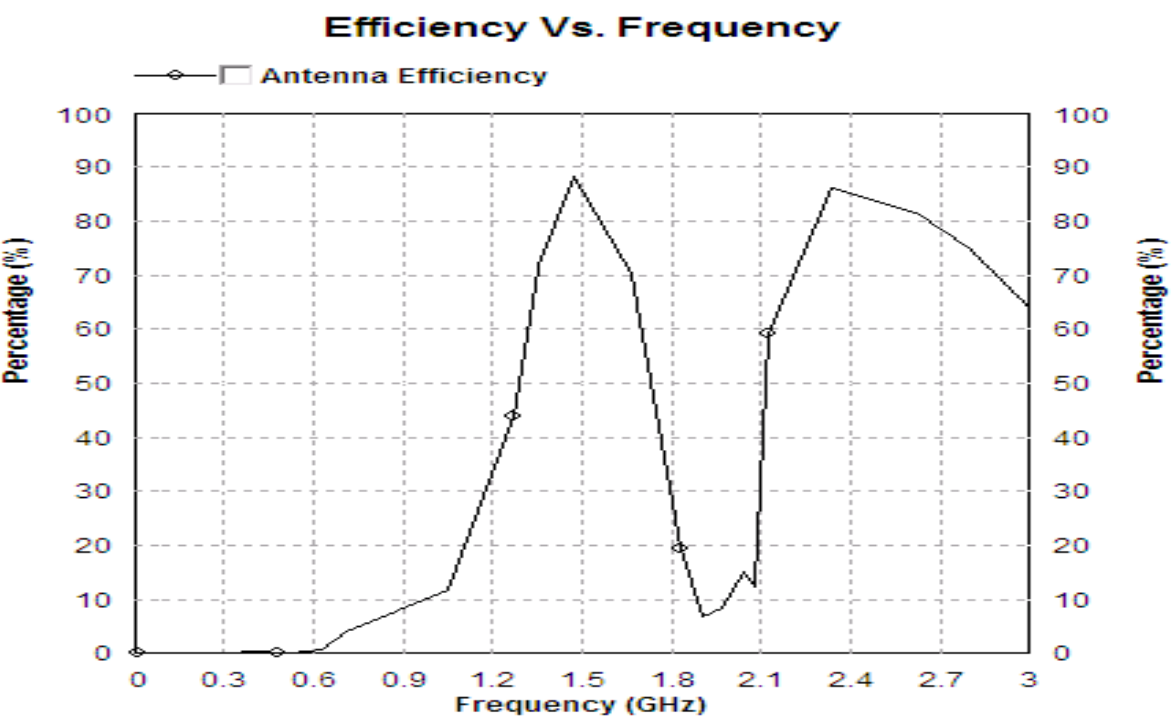

Fig.5: Directivity Vs Frequency curve 
It is shown that the directivity is $4.97077 \mathrm{dBi}$ at $1.90826 \mathrm{GHz}$.

Next important curve is antenna efficiency which is given as -

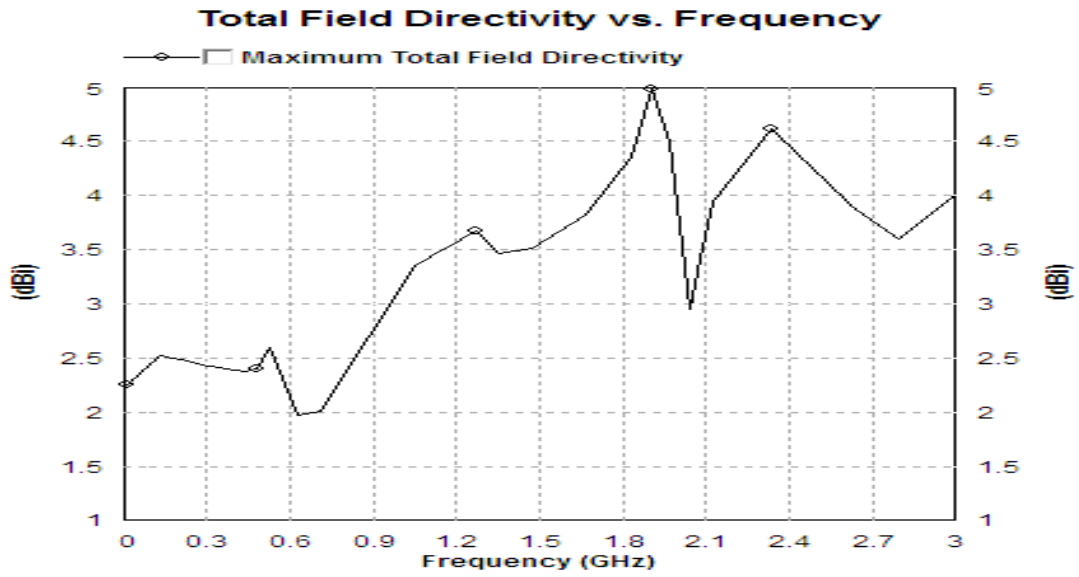

Fig.6: Antenna efficiency Vs Frequency curve

The antenna efficiency is $87.88 \%$ at $1.47706 \mathrm{GHz}$.

The radiation efficiency curve is given as -

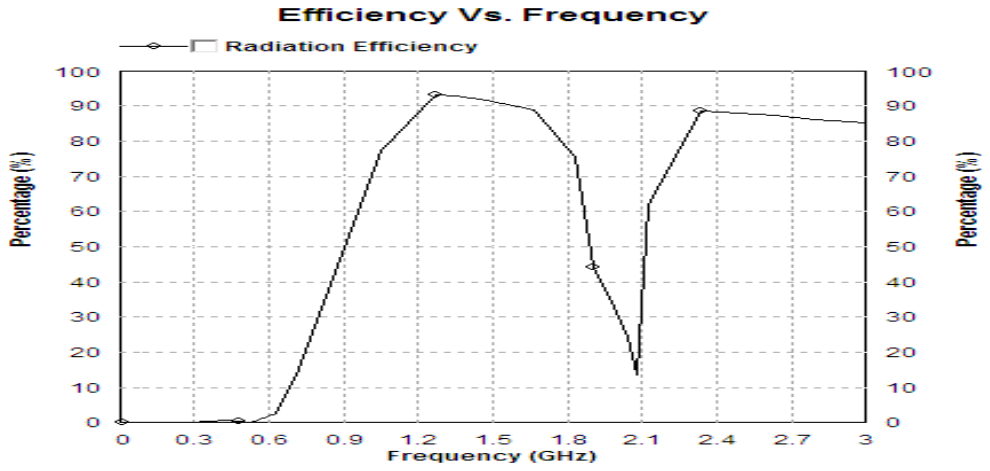

Fig.7: Radiation efficiency Vs Frequency curve

\section{Conclusion}

Finally S-shaped Microstrip patch antenna is analyzed using IE3D software Ver. 15.2. The Obtained percentage fractional bandwidths are $-7.79 \%$ at $0.262921 \mathrm{GHz}$ band, $13.45 \%$ at $1.53034 \mathrm{GHz}$ band, $28.0056 \%$ at $2.2382 \mathrm{GHz}$ band. We have also obtained a gain of $3.96 \mathrm{dBi}$ at $2.33945 \mathrm{GHz}$, a directivity of $4.97077 \mathrm{dBi}$ at $1.90826 \mathrm{GHz}$, antenna efficiency of $87.88 \%$ at $1.47706 \mathrm{GHz}$, radiation efficiency of $93.06 \%$ at $1.27523 \mathrm{GHz}$.

Further improvement of enhancing the gain and bandwidth of Microstrip patch antenna using different technique is still in progress.

\section{Acknowledgement}

The authors are highly thankful to Electronics and Communication Engineering Department of M.M.M. Engineering College, Gorakhpur for providing the necessary help to carry out this study and work.

\section{References}

[1] Karim A. Hamad, "Design and Enhancement Bandwidth Rectangular Patch Antenna using Single Trapezoidal Slot Technique," ARPN Journal of Engineering and Applied Sciences, ISSN 1819-6608, VOL. 7, NO. 3, p.p.292-297, March 2012.

[2] Elangovan, G. and J. Rajapaul Perinbam, "Wideband E-Shaped Microstrip Antenna for Wireless Sensor Networks," American Journal of Applied Sciences, ISSN 1546-9239, p.p.89-92, 2012.

[3] Kaushik Malakar, S. M. Danish Abbas, Sudipta Chattopadhyay, "Stacked Stair-case patch antenna for High Gain and Ultra Wideband Applications,” IJECT Vol. 2, Issue 1, p.p.7-9, March 2011.

[4] Linxi Zhang, Qi Zhang, Chufeng Hu, "The Influence of Dielectric Constant on Bandwidth of U-notch Microstrip Patch Antenna," Proceedings of 2010 IEEE International Conference on Ultra-Wideband (ICUWB2010).

[5] E. Nishiyama, M. Aikawa and S. Egashira, "Stacked microstrip antenna for wideband and high gain," IEE Proc.-Microw. Antennas Propag., Vol. 151, No. 2, p.p.143-148, April 2004. 
[6] Dalia Nashaat, Hala A. Elsadek, Esamt Abdallah, Hadia Elhenawy, and Magdy Iskander, "Ultra-wideband Co-planar Boat Microstrip Patch Antenna with Modified Ground Plane by Using Electromagnetic Band Gap Structure (EBG) for Wireless Communication," Progress In Electromagnetics Research Symposium Proceedings, Moscow, Russia, p.p.1052-1056, August 2009.

[7] Amit Kumar Gupta, R.K. Prasad and Dr. D.K. Srivastava, "Design and Development of Dual E-shaped Microstrip patch antenna for bandwidth and gain enhancement," IJECET, ISSN: 0976-6464, Volume3, Issue3, Oct-Dec 2012.

[8] B-K Ang and B-K chung, “A Wideband E-shaped Microstrip Patch Antenna for 5-6 GHz Wireless communication,"Progress in Electromagnetics Research, Vol.75, p.p.397-407, 2007.

[9] K.L.Wong, "Compact and Broadband Microstrip Antennas" John Wiley, 2003.

[10] J.R.James, P.S. Hall and C. Wood, "Microstrip antenna theory and design" INSPEC/IEE, 1981.

[11] C.A.Balanis, “Antenna theory: analysis and design,” John Wiley and Sons, INC., New York, Third Edition, 2005, p.p.810-811.

[12] www.google.co.in

[13] www.ieeexplore.org 